04

\title{
Эрозионное воздействие микроструктурированного канала искры на поверхность плоского медного электрода
}

\author{
(C) А.А. Тренькин
}

Российский Федеральный ядерный центр Всероссийский научно-исследовательский институт экспериментальной фозики,

607190 Саров, Россия

e-mail: trenkin@ntc.vniief.ru

(Поступило в Редакцию 23 апреля 2018 г.)

С использованием $3 D$-оптического профилометра проведено исследование эрозионной области на поверхности плоского медного электрода, обусловленной воздействием микроструктурированного канала искрового разряда в воздухе атмосферного давления в промежутке острие-плоскость. Установлено, что указанные области представляют собой скопление микрократеров, определены их форма и размеры.

DOI: 10.21883/JTF.2019.02.47068.162-18

\section{Введение}

В наших предыдущих исследованиях искрового разряда в воздухе атмосферного давления в промежутке острие-плоскость были зарегистрированы динамика пространственной микроструктуры искры и ее эрозионное воздействие на плоский электрод [1].

На разрядный промежуток с генератора импульсов напряжения посредством кабельной линии подавался импульс напряжения амплитудой $25 \mathrm{kV}$ и длительность фронта по уровню $0.1-0.9$ около $7 \mathrm{~ns}$. Электрод-острие длиной $5 \mathrm{~cm}$, диаметром $15 \mathrm{~mm}$, с углом при вершине $80^{\circ}$ и радиусом кривизны $0.2 \mathrm{~mm}$ изготовлен из алюминиевого сплава. Плоским электродом служила медная пластина толщиной $2 \mathrm{~mm}$ и размером рабочей поверхности $50 \times 20 \mathrm{~mm}^{2}$. Межэлектродный зазор составлял $3.5 \mathrm{~mm}$.

Для получения автографа разряда плоский электрод полировался до зеркального блеска, после чего на разрядный промежуток подавался один импульс напряжения.

После пробоя промежутка в разрядной цепи возникал колебательный процесс с экспоненциальным затуханием тока и напряжения. Длительность полуволны составляла $0.5 \mu \mathrm{s}$, амплитуда тока и время его затухания соответственно - $1.5 \mathrm{kA}$ и $2 \mu \mathrm{s}[1]$.

Было обнаружено, что на начальной стадии разряд развивается в форме микроканальной структуры - пучка большого количества каналов микронного диаметра. Динамика разряда на временах от единиц до десятков наносекунд включает развитие микроканалов от острия вглубь разрядного промежутка, ветвление, расширение микроканалов, формирование общего фронта ударной волны искры и его движение [1].

Одновременно с этим была зарегистрирована обусловленная воздействием разряда эрозионная микроструктура на поверхности плоского электрода, представляю- щая собой скопление микрократеров диаметрами от 5 до $35 \mu \mathrm{m}[1]$.

Следует, однако, отметить, что в [1] микроструктура поверхности электрода исследовалась с помощью оптического микроскопа, при этом следы воздействия наблюдались в виде темных точек или пятен, отождествляемых с микрократерами. Однако относительно слабое пространственное разрешение микроскопа не позволяло детализировать характеристики эрозионных областей.

В этой связи в целях продолжения исследований в этом направлении представляет интерес более детальное исследование эрозионных областей на поверхности плоского медного электрода.

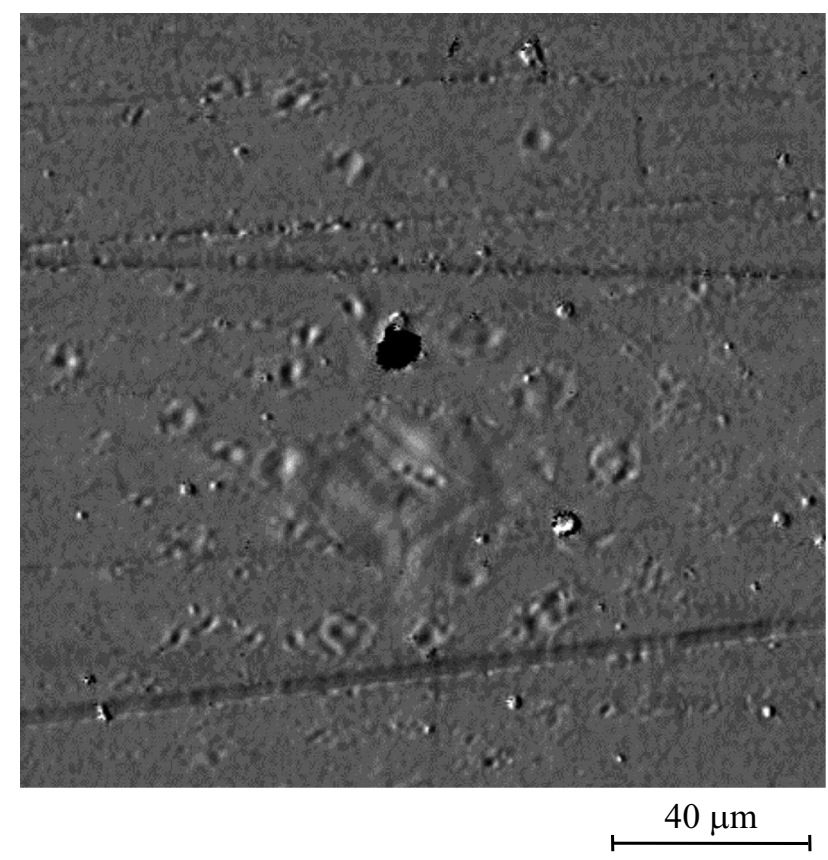

Рис. 1. Участок эрозионной области на поверхности плоского медного электрода. 


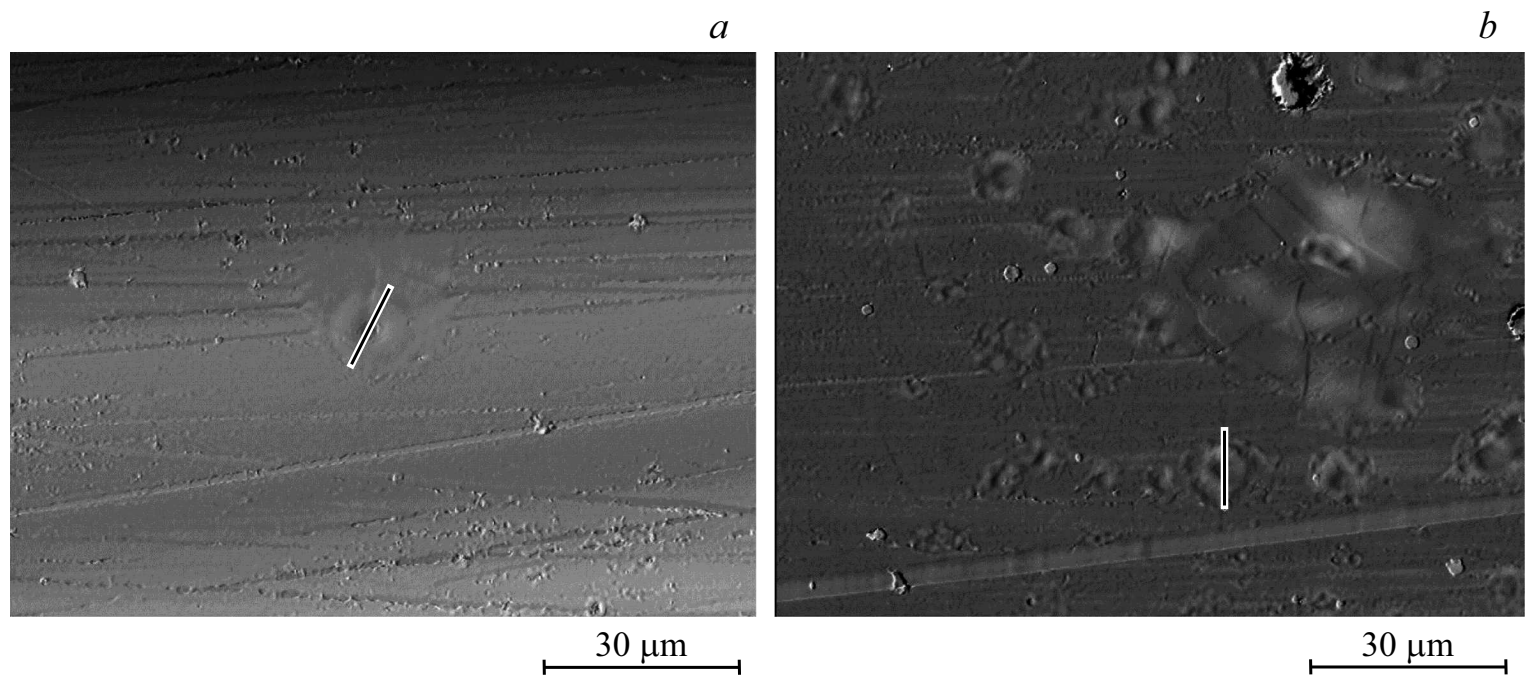

Рис. 2. Увеличенные изображения эрозионной области на поверхности плоского медного электрода. Черные отрезки обозначают путь для построения профиля поверхности.

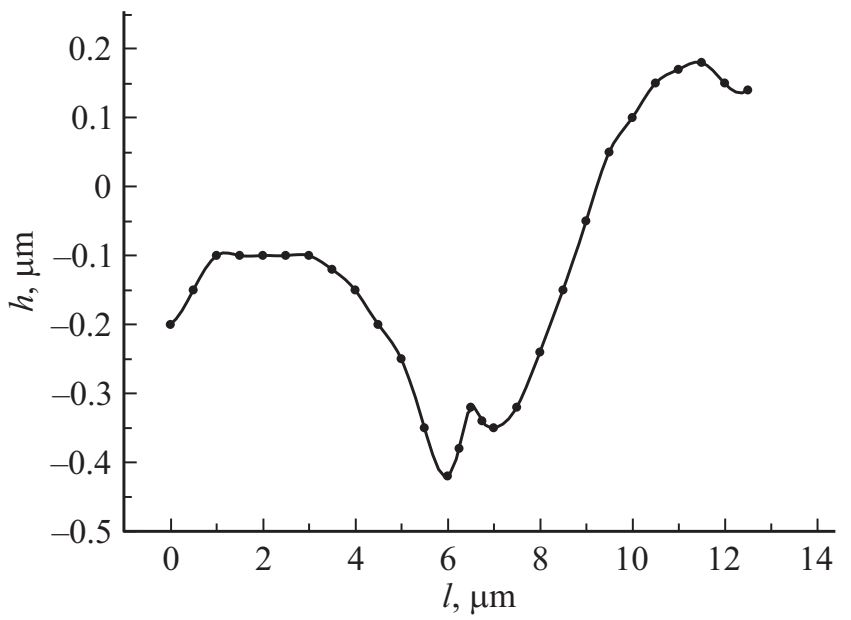

Рис. 3. Профилограмма поверхности вдоль пути $l$, обозначенного на рис. 2, а.

\section{Экспериментальные результаты и их обсуждение}

Исследование области воздействия искрового разряда на поверхность плоского электрода осуществлялось посредством $3 D$-оптического профилометра. Размер области воздействия составляет около $160 \mu \mathrm{m}$. На рис. 1 представлены результаты визуализации участка эрозионной области на поверхности плоского медного электрода. Видно, что указанная область представляет собой скопление микрократеров. На рис. 2 представлены изображения с большим увеличением, позволяющие детализировать характеристики отдельных микрократеров, а на рис. 3 и 4 представлены соответствующие профили отдельных микрократеров, приведенных на рис. 2.

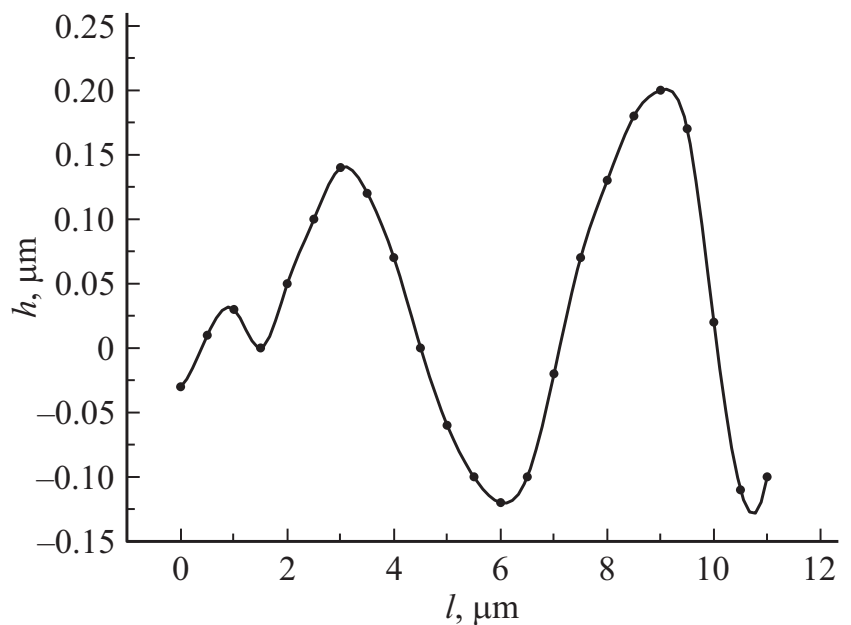

Рис. 4. Профилограмма поверхности вдоль пути $l$, обозначенного на рис. $2, b$.

Микрократеры представляют собой углубления в центральной области и кольцевые полусферические валики на периферии.

Для относительно крупных микрократеров ширина валиков составляет от 2 до $5 \mu \mathrm{m}$, диаметры углублений составляют от 2 до $4 \mu \mathrm{m}$, а их глубина от 0.1 до $0.4 \mu \mathrm{m}$. При этом дно некоторых микрократеров имеет плоскую форму или даже выступ в центральной части (рис. 3), в то время как другие микрократеры имеют чашеобразную форму углубления (рис. 4).

В структуре автографа присутствуют также микрократеры меньших размеров диаметром около $1 \mu \mathrm{m}$ и менее. Можно отметить сходство морфологии обнаруженных здесь микрократеров и микрократеров, зарегистрированных на поверхности стального электрода [2]. Однако на стальном электроде в структуре автографа 
разряда помимо микрократеров регистрировались еще и дорожки, отсутствующие на медном электроде. В то же время в работе [3] в близкой геометрии разрядного промежутка валики на границах микрократеров на медном электроде не регистрировались. Возможно это связано с существенно более низким энерговкладом в [3] относительно [1].

Оценка поверхностной концентрации микрократеров дает величину $(3-5) \cdot 10^{3} \mathrm{~mm}^{-2}$. Полученное значение следует рассматривать как оценку снизу. Одной из причин этого является относительно низкое качество полировки поверхности электрода. Поэтому при подсчете микрократеров в основном учитывались относительно крупные микрократеры, хорошо различимые на фоне рельефа поверхности. Другой причиной может являться сильная эрозия электрода. В этом случае возможно слияние нескольких микрократеров в один, а также выброс материала электрода из крупных микрократеров, что не позволяет идентифицировать наличие микрократеров в области его осаждения (см., например, рис. 2, a).

\section{Заключение}

С использованием $3 D$-оптического профилометра осуществлено исследование эрозионных областей на поверхности плоского медного электрода, обусловленных воздействием искрового разряда в воздухе атмосферного давления в промежутке острие-плоскость длиной $3.5 \mathrm{~mm}$.

Установлено, что указанные области представляют собой скопление микрократеров, каждый из которых представляет собой углубление в центральной области и кольцевой полусферический валик на периферии.

Определены геометрические параметры микрократеров. Для относительно крупных микрократеров ширина валиков составляет от 2 до $5 \mu \mathrm{m}$, диаметры углублений составляют от 2 до $4 \mu \mathrm{m}$, а их глубина - от 0.1 до $0.4 \mu \mathrm{m}$.

Обнаружены две морфологические формы микрократеров: в одном случае дно микрократеров имеет плоскую форму или даже выступ в его центральной части, во втором случае форма углубления микрократеров является чашеобразной.

Автор благодарен В.И. Карелину за поддержку работы, а также сотрудникам ЦНИИХМ за получение профилограмм.

\section{Список литературы}

[1] Алмазова К.И., Белоногов А.Н., Боровков В.В., Горелов Е.В., Морозов И.В., Тренькин А.А., Харитонов С.Ю. // ЖТФ. 2018. Т. 88. Вып. 6. С. 823-827.

[2] Карелин В.И., Тренькин А.А., Шибитов Ю.М., Блинова О.М., Ясников И.С. // ЖТФ. 2016. Т. 86. Вып. 10. С. 54-57.

[3] Карелин В.И., Тренькин А.А., Шибитов Ю.М., Блинова О.М., Ясников И.С. // ЖТФ. 2017. Т. 87. Вып. 9. С. 14111415. 